\title{
Matrix Metalloproteinases and Tissue Inhibitor of Metalloproteinases Are Essential for the Inflammatory Response in Cancer Cells
}

\author{
Jun Sun ${ }^{1,2,3}$ \\ ${ }^{1}$ Gastroenterology \& Hepatology Division, Department of Medicine, University of Rochester, Box 646, 601 Elmwood Avenue, \\ Rochester, NY 14642, USA \\ ${ }^{2}$ Department of Microbiology and Immunology, University of Rochester, Box 646, 601 Elmwood Avenue, Rochester, NY 14642, USA \\ ${ }^{3}$ James Wilmot Cancer Center, University of Rochester, Box 646, 601 Elmwood Avenue, Rochester, NY 14642, USA
}

Correspondence should be addressed to Jun Sun, jun_sun@urmc.rochester.edu

Received 9 March 2010; Accepted 16 June 2010

Academic Editor: Hiroshi Shibuya

Copyright () 2010 Jun Sun. This is an open access article distributed under the Creative Commons Attribution License, which permits unrestricted use, distribution, and reproduction in any medium, provided the original work is properly cited.

Inflammation plays a critical role in the development of cancer. Matrix Metalloproteinase (MMP) functions in the remodeling of the extracellular matrix that is integral for many normal and pathological processes such as morphogenesis, angiogenesis, tissue repair, and tumor invasion. The tissue inhibitor of metalloproteinases (TIMPs) family regulates the activity of multifunctional metalloproteinases. In this paper, we discuss the role and mechanism of MMP and TIMP in regulating inflammation responses in solid tumors. We discuss the mechanism of MMP and inflammation in melanoma, colon cancer, breast cancer, and prostate cancer. We highlight the roles of the TIMP-2 in modulating the proinflammatory NF- $\kappa \mathrm{B}$ pathway in melanoma and lung caner cells. Based on the molecular mechanisms of TIMPs and MMPs in inflammation and cancer, we can design new strategies for cancer therapy.

\section{Introduction}

MMPs belong to a family of structurally related proteolytic enzymes that mediate degradation of the extracellular matrix and the basement of membranes [1-3]. High levels of MMP activity have been linked to tumor growth, invasion, and angiogenesis inflammation and may even work in a nonproteolytic manner $[4,5]$. The tissue inhibitor of metalloproteinases family, including TIMP-1, 2, 3, and 4, regulates the activity of multifunctional metalloproteinases $[6,7]$. Among TIMP members, TIMP-2 is most frequently investigated because it is a unique member of the TIMP family and involved in cancer progression and metastasis.

Recent studies have begun to unravel molecular pathways linking inflammation and cancer $[8,9]$. Inflammatory conditions can initiate or promote oncogenic transformation and genetic and epigenetic changes in malignant cells. An inflammatory microenvironment further supports tumor progression [10-12]. Cancer-associated inflammation is marked by the presence of specific inflammatory cells and inflammatory mediators, including cytokines and chemokines. Nuclear factor $-\kappa \mathrm{B}(\mathrm{NF}-\kappa \mathrm{B})$ transcription factor plays an essential role in innate and adaptive immune responses, cell proliferation, apoptosis, and tumorigenesis [13-15]. Constitutive activation of NF- $\kappa \mathrm{B}$ has been directly implicated in tumorigenesis of various cancer types [16-18]. Recent evidence also suggests a crucial role for signal transducer and activator of transcription (STAT) family in selectively inducing and maintaining a procarcinogenic inflammatory microenvironment, both at the initiation of malignant transformation and during cancer progression [11]. The targeting of inflammatory mediators (chemokines and cytokines, such as TNF- $\alpha$ and IL-1 $\beta$ ), key transcription factors involved in inflammation (such as NF- $\kappa$ B and STAT), or inflammatory cells decreases the incidence and spread of cancer [10]. Therefore, antiinflammation is an essential strategy for the cancer therapy.

In this paper, we discuss the mechanisms of MMPs and TIMPs in regulating inflammation in the cancer cells. We highlighted the interaction among TIMPs, MMPs, and inflammatory pathways. We focus on the roles of MMP and 
TIMP-2 in modulating inflammation and cancer progression in solid tumors. We also discuss the progress on the therapeutic researches and lessons learned from the failed clinical trials for MMP inhibitors. Increasing studies demonstrate that chronic inflammation is associated with outcome of cancers [19]. Therefore, insights in the molecular mechanisms of MMP and TIMP in inflammation and cancer will provide promising opportunities for therapeutical intervention.

\section{MMPs and TIMPs}

The MMP family includes over 20 zinc-dependent enzymes that share common functional domains. These enzymes were initially characterized by their extensive ability to degrade extracellular matrix proteins including collagens, laminin, fibronectin, vitronectin, aggrecan, enactin, tenascin, elastin, and proteoglycans [20]. Recent studies further demonstrate that MMPs actually cleave many other types of peptides and proteins and have a myriad of other important functions independent of proteolytic activity [21].

The tissue inhibitors of metalloproteinases or TIMPs consist of a small family of four homologous and low molecular weight proteins. TIMPs suppress MMP activity critical for extracellular matrix turnover associated with both physiologic and pathologic tissue remodeling. TIMP concentrations generally far exceed the concentration of MMPs in tissue and extracellular fluids, thereby limiting their proteolytic activity to focal pericellular sites [22].

TIMPs, aside from inhibition MMP, also are involved in other biological process required for metastasis and angiogenesis [23]. TIMP-2, a unique member of this family, was discovered in 1989 [24]. TIMP-2 selectively blocked human microvascular endothelial cell growth in vitro in response to proangiogenic factors such as fibroblast growth factor 2(FGF-2) or vascular endothelial growth factor A (VEGF A) [25]. Other distinguishing features of TIMP-2 are that it is the only member that is not nested within the gene structure of the synapsin gene family and the timp-2 gene also contains a large first intron $(>60 \mathrm{kB})$. TIMP-2 could suppress receptor tyrosine kinase signaling independent of metalloproteinase inhibition [25]. TIMP-2 bridges the interaction between the MMP-2 zymogen and MT1-MMP. In contrast to the usual inhibitory role, at low TIMP-2 concentration, an adjacent TIMP-2-free MT1-MMP can effectively activate proMMP2. However, at high TIMP-2 concentration, all of the cell surface MT1-MMP undergoes complex formation with TIMP-2, thereby inhibiting proMMP-2 activation [26]. The cellular mechanism for the control of MT1-MMP catalytic activity involved concurrent reciprocal modulation of TIMP2 expression by ERK1/2 and p38 MAPKs. Inhibition of ERK1/2 phosphorylation decreased TIMP-2 production, and downregulation of p38 MAPK activity enhanced TIMP-2 synthesis [26]. Recently, TIMP-1 is shown to bind to CD63, thus regulating cell survival and polarization [27]. TIMP3 is also assigned a new function independent of its MMPinhibitory activity [28]. TIMP3 blocks the binding of VEGF to VEGF receptor-2 and inhibits downstream signaling and angiogenesis [28].

\section{General Roles of MMPs and TIMPs in Cancers}

Tumor cells produce enzymes that destroy the matrix barriers surrounding the tumor, permitting invasion into surrounding connective tissues, entry and exit from blood vessels, and metastasis to distant organs. Enzymes that degrade the extracellular matrix (ECM) have long been viewed as essential for tumor progression. MMPs are able to degrade virtually all ECM components. Therefore, classically, MMPs were recognized as being produced and secreted by tumor cells, degrading basement membrane and extracellular matrix components, thereby facilitating tumor cell invasion and metastasis. Now, we know that MMPs are frequently produced by surrounding stromal cells, including fibroblasts and infiltrating inflammatory cells. One explanation for this phenomenon is that cancer cells produce Extracellular Matrix Metalloproteinase Inducer, a cell surface glycoprotein, which directly stimulates fibroblasts to produce MMP1, 2, 3, and MMP14 [29].

Recent studies further demonstrate that MMPs contribute to multiple steps of tumor progression in addition to invasion, including tumor promotion, angiogenesis, and the establishment and growth of metastatic lesions in distant organ sites. MMPs are upregulated in virtually all human and animal tumors as well as in most tumor cell lines [20, 30]. The stage of tumor progression is positively correlated with the expression of MMP family members (MMP-1/interstitial collagenase; MMPs 2, 3, 7, 9, 11, and 14) [21]. Moreover, MMPs also solubilize cell surface and matrix-bound factors that can then act in an autocrine or paracrine manner to influence cellular properties such as growth, death, and migration. Changes in MMP levels can markedly affect the invasive behavior of tumor cells and their ability to metastasize in experimental animal models [31]. Taken together, these studies suggest that MMPs are important contributors to tumor progression.

TIMPs are originally known to inhibit the MMP activities. TIMP is downregulated or silenced in a variety of human cancer cell lines. TIMPs also are involved in other biological processes in cancer. Promoter hypermethylation and lost expression of TIMP-2 gene have been reported in prostate cells and tumor samples [32]. Overexpression of TIMPs reduced experimental metastasis of melanoma $[33,34]$. Intraperitoneal injection of recombinant TIMP-1 is explored in lung cancer [35]. Transgenic studies reveal that mouse $3 \mathrm{~T} 3$ cells became tumorigenic after antisense depletion of TIMP-1 [36]. TIMP-1 overproduction slowed chemical carcinogenesis in skin and liver carcinogenesis in transgenic mice [37, 38]. In addition, TIMPs have shown apoptosis-inducing properties (TIMP3). Overexpression of TIMP-3 resulted in apoptosis of A549 lung cancer cells and AdCMVTIMP3 up-regulated the expression of p53, Fas ligand, TNFR1, and TNFR2 on these cells. Adenoviral delivery of TIMP-3 gene inhibited the growth of preestablished A549 tumours in Balb/c nude mice, and was associated with a greater therapeutic effect than either TIMP1 or -2 gene delivery. These findings establish the potential of adenoviral gene delivery of TIMP3 as a therapeutic agent for selected lung cancers [39]. Study using breast cancer samples 


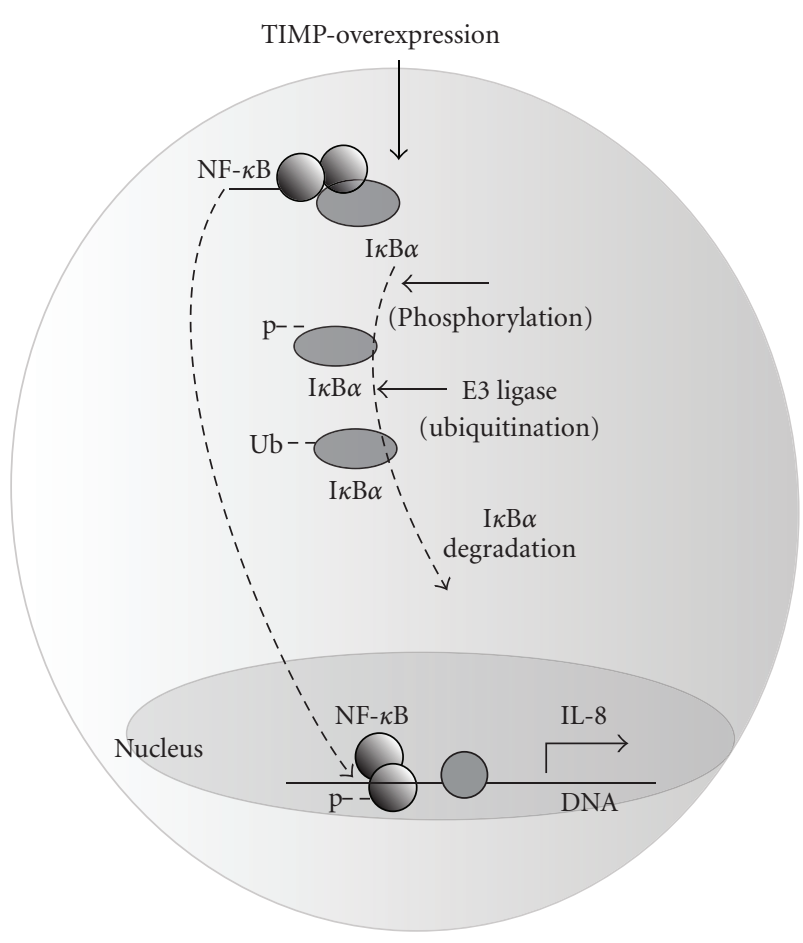

FIgURE 1: TIMP-2 expression and NF- $\kappa$ B activity. The effects of TIMP-2 on the NF- $\kappa \mathrm{B}$ pathway include the decreased basal level of $\mathrm{I} \kappa \mathrm{B} \alpha$, increased phosphorylation of $\mathrm{I} \kappa \mathrm{B} \alpha$ and NF- $\kappa \mathrm{B}$, increased transcriptional NF- $\kappa$ B activity, and elevated IL- 8 levels in the TIMP2-overexpressed cells.

demonstrates that the expressions of MMP-1, MMP-2, MMP-3, MMP-9, urokinase-type PA, and tissue-type PA, and inhibitors (TIMP-1 and TIMP-2) were stronger or equivalent in tumor cells than in fibroblasts or inflammatory cells within the tumor section [40]. Overall, studies on MMPs and TIMPS in cancer provide the rationale for developing cancer drugs that target TIMP and MMP activities.

\section{MMPs and Cytokines}

The activity of MMP is under tight control at several levels in vivo: transcriptionally by growth factors, hormones, cytokines, and oncogenes; posttranscriptionally by alteration of mRNA stability; and at the enzymatic activity level by activation of the latent form and inhibition by TIMPs [23].

MMPs are generally expressed in very low amounts and their transcription is regulated either positively or negatively by cytokines and growth factors such as inflammatory interleukins (IL-1, IL-4, IL-6, TNF) or transforming growth factors (EGF, HGF, TGF $\beta$ ) [41]. The importance of cytokines such as TNF- $\alpha$, interleukin (IL)-1, and IL-6 in stimulating production of MMPs in disease has been emphasized. They can be seen as important therapeutic targets for intervention in cancers. Increasing evidences demonstrate that MMPs play an important role in acute as well as chronic inflammation $[5,42]$. CCL8/MCP-2 is processed by MMP-1 and MMP3. The proteolytic cleavage of CCL8 can counteract the antitumor capacity of this chemokine in a melanoma model
[43]. The proteolytic cleavage of a chemokine by MMPs can have great impact in a clinically relevant setting of tumor development [5].

The transcription of TIMPs is regulated by similar cytokines and growth factors that control MMP expression, that is, TGF $\beta, \mathrm{TNF} \alpha$, IL-1, and IL-6 [44]. However, in macrophages IL- 4 and IFN gamma released by lymphocytes suppress metalloproteinase biosynthesis without affecting TIMP production $[45,46]$.

IL-10 is a cytokine with potent anti-inflammatory properties, repressing the expression of inflammatory cytokines such as TNF-alpha, IL-6, and IL-1. IL-10 enhances TIMP1 production while decreasing metalloproteinase biosynthesis in tissue macrophages, and blood monocytes TIMP2 production was not affected. IL-10 regulation was cell type specific, as it had no effect on the production of metalloproteinases or TIMP by human fibroblasts [47]. In nonimmortalized primary human prostate cell strains, IL10 activation of the IL-10 receptor blocked MMP-2 and membrane type 1 (MT1)-MMP transcription and protein synthesis. IL-10 induced protein(s) binding to a putative "silencer element" downstream of the p53 binding site. The data show that IL-10 blocks IGF-I activation of MMP-2 and MT1-MMP mRNA expression and protein synthesis in prostate cells [48]. In summary, IL-10 has a potent and unique effect by enhancing TIMP production while decreasing metalloproteinase biosynthesis in cells.

\section{TIMP-2 Directly Modulates the NF- $\kappa$ B Pathway Activity}

$\mathrm{NF}-\kappa \mathrm{B}$ is an inducible dimeric transcription factor composed of the RelA (p65) and NF- $\kappa$ B1 (p50) subunits [49]. $\mathrm{NF}-\kappa \mathrm{B}$ activation involves its release from its inhibitor, $\mathrm{I} \kappa \mathrm{B} \alpha$, and its subsequent translocation from the cytoplasm to the nucleus, where it binds to promoters of target genes. Many proinflammatory cytokines and chemokines, such as IL-8, IL-6, and TNF, are targets of NF- $\kappa \mathrm{B}$ regulation $[50,51]$. Using stable melanoma cell lines, parental A2058, A2058T21 overexpressing TIMP-2, and A2058T2R-7 underexpressing TIMP-2, we demonstrate that the IL- 8 secretion and IL- 8 mRNA expression significantly increased in the A2058T21 overexpressing TIMP-2 [52]. We also found that in the TIMP-2 overexpressed cells the basal level of $\mathrm{I} \kappa \mathrm{B} \alpha$ was lower than that in the parental A2058 cells. I $\kappa \mathrm{B} \alpha$ degradation involves phosphorylation, ubiquitination, and subsequent proteasomal degradation. Phospho- $\mathrm{I} \kappa \mathrm{B} \alpha$ was increased in the TIMP-2 over-expressed cells, which is consistent with the reduced level of total $\mathrm{I} \kappa \mathrm{B} \alpha$. TIMP-2 expression is able to elevate p65 phosphorylation, thus increasing the NF$\kappa \mathrm{B}$ activity (total $\mathrm{I} \kappa \mathrm{B} \alpha \downarrow=\mathrm{p}-\mathrm{I} \kappa \mathrm{B} \alpha \uparrow=\mathrm{p}-\mathrm{p} 65 \uparrow=$ activity of NF- $\kappa \mathrm{B} \uparrow)$. TIMP-2 expression directly upregulates the transcriptional activity of NF- $\kappa \mathrm{B}[52]$.

Apoptosis is one of the biological effects regulated by the NF- $\kappa \mathrm{B}$ pathway. TIMP-2 overexpression is able to protect cells from apoptosis. TIMP-2 was shown to stimulate proliferation in human cells, including osteosarcoma cells [53], fibroblasts [54], and A549 lung adenocarcinoma cells [55]. Our data suggest that TIMP-2 over-expression is able to 
protect cells from apoptosis in human melanoma A2058 cells [52]. It is consistent with the previous studies that TIMP-2 overexpression protects B16F10 melanoma cells from apoptosis reduced [23]. Overall, these data indicate that TIPM2 modulates other relevant aspects of the melanomatatic phenotypes including cell proliferation and cell survival.

In lung cancer cells, the NF- $\kappa \mathrm{B}$ activity was increased by exposure to TIMP-2 [56]. The NF- $\kappa \mathrm{B}$ transcription factor is known to act as a tumor promoter. It is intriguing that TIMP-2 upregulates NF- $\kappa \mathrm{B}$ activity, whereas TIMP-2overexpression can prevent tumor invasion [23]. TIMP-2 upregulation of NF- $\kappa \mathrm{B}$ activity may inhibit tumor growth in the early stage because other data suggest a dual function of $\mathrm{NF}-\kappa \mathrm{B}$ during tumor progression. In the early stages, NF- $\kappa \mathrm{B}$ inhibits tumor growth; as further mutations lead to a loss of tumor suppressor expression, the oncogenic functions of $\mathrm{NF}-\kappa \mathrm{B}$ become unleashed, allowing it to actively contribute to tumorigenesis [57].

Overall, TIMP-2 expression can directly modulate the NF- $\kappa$ B pathway (Figure 1 ). The effects of TIMP-2 on the $\mathrm{NF}-\kappa \mathrm{B}$ pathway include the decreased basal level of $\mathrm{I} \kappa \mathrm{B} \alpha$, increased phosphorylation of $\mathrm{I} \kappa \mathrm{B} \alpha$ and $\mathrm{NF}-\kappa \mathrm{B}$, increased transcriptional NF- $\kappa \mathrm{B}$ activity, and elevated IL- 8 levels in the TIMP-2-overexpressed A2028T2-1 cells. Consequently, TIMP-2 over-expression was able to protect cells from apoptosis [52]. Our results and other's publications show that TIMP-2 over-expression is sufficient to increase the NF- $\kappa \mathrm{B}$ activity and protect cells from apoptosis. These data emphasize the critical role of TIMP-2 in modulating cell survival and invasion through the NF- $\kappa \mathrm{B}$ activity.

\section{STAT, MMPs, and TIMPs}

The signal transducers and activators of transcription (STATs) are members of a ubiquitously expressed family of transcription factors activated in response to growth factors and cytokines. STAT3 has been shown to be an oncogene [58]. Many types of human cancers express constitutively active STAT3 [58]. Increasing evidences demonstrate that STAT regulates MMPs [59]. STAT3 up-regulates TIMP-1 in certain cell lines. For example, A significant association exists between the expression of the phosphorylated/active form of STAT3 (pSTAT3) and that of TIMP1. Importantly, STAT3 activation correlated significantly with a lower frequency of vascular and lymphatic invasion. STAT3 activation may modulate tumor invasiveness of breast cancer by regulating TIMP1 expression [60].

TIMP-1 gene is up-regulated by IL-6 [61]. A molecular biology study identified that TIMP-1 is a downstream target of STAT3. Timp-1 gene possesses an IL-6/oncostatin M (OSM) response element. Within this element, there are two functional binding sites for transcription factors activator protein-1 (AP-1) and STAT. IL-6/OSM stimulation induces binding of STAT3 to the IL-6/OSM response element, while binding of the AP-1 protein was constitutive. Binding sites for both AP-1 and STAT3 are necessary for full responsiveness of the TIMP-1 promoter to IL-6/OSM, as shown by deletion and mutation analysis. Furthermore, the entire

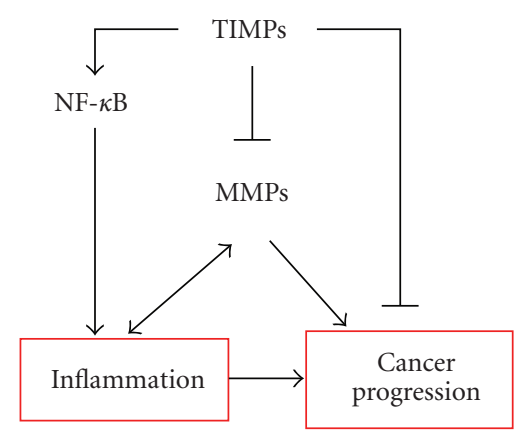

FIGURE 2: TIMPs and MMPs in inflammation and tumor progression. TIMPs functions in inhibition of MMP activity, activation of the proinflammatory NF- $\kappa$ B pathway, and regulation of inflammation. MMPs play a critical role in tumor progression. Inflammatory cytokines enhance the dysfunction of MMPs, whereas MMPs increase inflammation in the tissue. TIMPs may modulate critical signaling pathways for inflammation and cancer independent of metalloproteinase inhibition.

IL-6/OSM response element conferred responsiveness onto a heterologous promoter [61]. As a downstream target of STAT3, TIMP1 mediates the antiapoptotic effects of STAT3 [62].

The IL-10 receptor is in the JAK/STAT class of receptors [63]. IL-10 blocked MMP-2 and MT1-MMP transcription and protein synthesis in an IL-10 receptor-dependent manner [48]. Therefore, it will be interesting to investigate whether the regulation of IL-10 on TIMP and MMP is through the JAK/STAT pathway.

\section{Conclusion and Future Studies}

Based on the important role of MMPs cancer and successful drug trials in mice, numerous clinical trials were initiated in the 1990s to test the effectiveness of hydroxamic acid-derived MMP inhibitors (MMPIs) in patients with cancer. However, these drugs have languished. Retrospective assessment of the design of clinical trials has led to the recognition that specific MMPIs used in conjunction with cytotoxic chemotherapy in early stage, rather than late stage cancer, needs future consideration [31]. The important lessons learned from the MPI experience may be of great value for future studies of MPIs and for cancer drug development in general [31].

Eempiric evidence for control and modulation of MMP transcription and/or activation by several naturally occurring substances, such as flavonoids, green tea polyphenols, and curcumin, represent novel options for the control of MMP activity even in early tumor stages. Additionally, these substances have little or no toxic side effects and good bioavailability, and therefore their continuing analysis provides intriguing insight into tumor pathophysiology and possibly new therapeutic options [64].

Increasing evidences demonstrate that TIMPs could modulate critical signaling pathways independent of metalloproteinase inhibition. These findings suggest that further understanding of the antiangiogenic activity of TIMPs might be exploited in human cancer therapy. 
Cytokine and chemokines display diverse effects for enhancing immunity to tumor-associated antigens, regulating angiogenesis, promoting proliferation/antiapoptosis of tumor cells, and mediating tumor cell invasion and trafficking in an organ-specific manner that leads to metastases. They can be seen as important therapeutic targets for intervention in cancer [65].

Cancer progression is known to be involved in the $\mathrm{NF}-\kappa \mathrm{B}$ and STAT pathways. NF- $\kappa \mathrm{B}$ is an important target to prevent metastasis and provide a rationale for further study of this transcription factor in metastatic disease [66]. TIMPs functions in inhibition of MMP activity, activation of the proinflammatory NF- $\kappa \mathrm{B}$ pathway, and regulation of inflammation. MMPs play a critical role in tumor progression. Inflammatory cytokines enhance the dysfunction of MMPs, whereas MMPs increase inflammation in the tissue (Figure 2). Therefore, understanding inflammation regulated by MMP and TIMP will provide the platform for the design of therapies. The therapeutic implications of anti-inflammation and anticancer will be an exciting and promising field of translational studies.

\section{Acknowledgments}

The author thanks all present and former members of my group for their contribution to his own work on inflammation, melanoma, and colon cancer. She also thanks Yuxuan Xia for critical editing of this paper. This work was supported by NIDDK KO1 DK075386 and the American Society Research Scholar Grant RSG-09-075-01-MBC to J. Sun.

\section{References}

[1] L. A. Liotta, W. Stetler-Stevenson, and P. S. Steeg, "Metastasis suppressor genes," Important Advances in Oncology, pp. 85100, 1991.

[2] L. A. Liotta and W. G. Stetler-Stevenson, "Metalloproteinases and cancer invasion," Seminars in Cancer Biology, vol. 1, no. 2, pp. 99-106, 1990.

[3] J. S. Rao, "Molecular mechanisms of glioma invasiveness: the role of proteases," Nature Reviews Cancer, vol. 3, no. 7, pp. 489-501, 2003.

[4] Z. L. Gokaslan, S. K. Chintala, J. E. York et al., "Expression and role of matrix metalloproteinases MMP-2 and MMP-9 in human spinal column tumors," Clinical and Experimental Metastasis, vol. 16, no. 8, pp. 721-728, 1998.

[5] K. Kessenbrock, V. Plaks, and Z. Werb, "Matrix metalloproteinases: regulators of the tumor microenvironment," Cell, vol. 141, no. 1, pp. 52-67, 2010.

[6] W. G. Stetler-Stevenson and D.-W. Seo, "TIMP-2: an endogenous inhibitor of angiogenesis," Trends in Molecular Medicine, vol. 11, no. 3, pp. 97-103, 2005.

[7] W. G. Stetler-Stevenson, L. A. Liotta, and D. E. Kleiner Jr., "Extracellular matrix 6: role of matrix metalloproteinases in tumor invasion and metastasis," FASEB Journal, vol. 7, no. 15, pp. 1434-1441, 1993.

[8] F. Balkwill and L. M. Coussens, "Cancer: an inflammatory link," Nature, vol. 431, no. 7007, pp. 405-406, 2004.

[9] L. M. Coussens and Z. Werb, "Inflammation and cancer," Nature, vol. 420, no. 6917, pp. 860-867, 2002.
[10] A. Mantovani, P. Allavena, A. Sica, and F. Balkwill, "Cancerrelated inflammation," Nature, vol. 454, no. 7203, pp. 436-444, 2008.

[11] H. Yu, D. Pardoll, and R. Jove, "STATs in cancer inflammation and immunity: a leading role for STAT3," Nature Reviews Cancer, vol. 9, no. 11, pp. 798-809, 2009.

[12] F. Colotta, P. Allavena, A. Sica, C. Garlanda, and A. Mantovani, "Cancer-related inflammation, the seventh hallmark of cancer: links to genetic instability," Carcinogenesis, vol. 30, no. 7, pp. 1073-1081, 2009.

[13] F. R. Greten and M. Karin, "The IKK/NF- $\kappa$ B activation pathway-a target for prevention and treatment of cancer," Cancer Letters, vol. 206, no. 2, pp. 193-199, 2004.

[14] M. S. Hayden and S. Ghosh, "Signaling to NF-kappaB," Genes \& Development, vol. 18, no. 18, pp. 2195-2224, 2004.

[15] M. Karin and F. R. Greten, "NF- $\kappa$ B: linking inflammation and immunity to cancer development and progression," Nature Reviews Immunology, vol. 5, no. 10, pp. 749-759, 2005.

[16] F. L. Meyskens Jr., J. A. Buckmeier, S. E. McNulty, and N. B. Tohidian, "Activation of nuclear factor- $\kappa \mathrm{B}$ in human metastatic melanoma cells and the effect of oxidative stress," Clinical Cancer Research, vol. 5, no. 5, pp. 1197-1202, 1999.

[17] R. L. Shattuck-Brandt and A. Richmond, "Enhanced degradation of $\mathrm{I}-\kappa \mathrm{B} \alpha$ contributes to endogenous activation of NF- $\kappa \mathrm{B}$ in Hs294T melanoma cells," Cancer Research, vol. 57, no. 14, pp. 3032-3039, 1997.

[18] K. I. Amiri and A. Richmond, "Role of nuclear factor- $\kappa \mathrm{B}$ in melanoma," Cancer and Metastasis Reviews, vol. 24, no. 2, pp. 301-313, 2005.

[19] R. Medzhitov, "Origin and physiological roles of inflammation," Nature, vol. 454, no. 7203, pp. 428-435, 2008.

[20] H. Nagase and J. F. Woessner Jr., "Matrix metalloproteinases," The Journal of Biological Chemistry, vol. 274, no. 31, pp. 21491-21494, 1999.

[21] C. M. Overall and C. López-Otín, "Strategies for MMP inhibition in cancer: innovations for the post-trial era," Nature Reviews Cancer, vol. 2, no. 9, pp. 657-672, 2002.

[22] W. G. Stetler-Stevenson, "Tissue inhibitors of metalloproteinases in cell signaling: metalloproteinase-independent biological activities," Science Signaling, vol. 1, no. 27, p. re6, 2008.

[23] P. Valente, G. Fassina, A. Melchiori et al., "TIMP-2 overexpression reduces invasion and angiogenesis and protects B16F10 melanoma cells from apoptosis," International Journal of Cancer, vol. 75, no. 2, pp. 246-253, 1998.

[24] W. G. Stetler-Stevenson, H. C. Krutzsch, and L. A. Liotta, "Tissue inhibitor of metalloproteinase (TIMP-2). A new member of the metalloproteinase inhibitor family," Journal of Biological Chemistry, vol. 264, no. 29, pp. 17374-17378, 1989.

[25] W. G. Stetler-Stevenson, "The tumor microenvironment: regulation by MMP-independent effects of tissue inhibitor of metalloproteinases-2," Cancer and Metastasis Reviews, vol. 27, no. 1, pp. 57-66, 2008.

[26] H. G. Munshi, Y. I. Wu, S. Mukhopadhyay et al., "Differential regulation of membrane type 1-matrix metalloproteinase activity by ERK 1/2- and p38 MAPK-modulated tissue inhibitor of metalloproteinases 2 expression controls transforming growth factor- $\beta 1$-induced pericellular collagenolysis," Journal of Biological Chemistry, vol. 279, no. 37, pp. 39042-39050, 2004.

[27] K.-K. Jung, X.-W. Liu, R. Chirco, R. Fridman, and H.-R. C. Kim, "Identification of CD63 as a tissue inhibitor of metalloproteinase-1 interacting cell surface protein," EMBO Journal, vol. 25, no. 17, pp. 3934-3942, 2006. 
[28] J. H. Qi, Q. Ebrahem, N. Moore et al., "A novel function for tissue inhibitor of metalloproteinases-3 (TIMP3): inhibition of angiogenesis by blockage of VEGF binding to VEGF receptor-2," Nature Medicine, vol. 9, no. 4, pp. 407-415, 2003.

[29] L. Yan, S. Zucker, and B. P. Toole, "Roles of the multifunctional glycoprotein, emmprin (basigin; CD147), in tumour progression," Thrombosis and Haemostasis, vol. 93, no. 2, pp. 199-204, 2005.

[30] E. A. Baker, F. G. Bergin, and D. J. Leaper, "Matrix metalloproteinases, their tissue inhibitors and colorectal cancer staging," British Journal of Surgery, vol. 87, no. 9, pp. 1215-1221, 2000.

[31] L. M. Coussens, B. Fingleton, and L. M. Matrisian, "Matrix metalloproteinase inhibitors and cancer: trials and tribulations," Science, vol. 295, no. 5564, pp. 2387-2392, 2002.

[32] S. M. Pulukuri, S. Patibandla, J. Patel, N. Estes, and J. S. Rao, "Epigenetic inactivation of the tissue inhibitor of metalloproteinase-2 (TIMP-2) gene in human prostate tumors," Oncogene, vol. 26, no. 36, pp. 5229-5237, 2007.

[33] A. M. P. Montgomery, B. M. Mueller, R. A. Reisfeld, S. M. Taylor, and Y. A. DeClerck, "Effect of tissue inhibitor of the matrix metalloproteinases-2 expression on the growth and spontaneous metastasis of a human melanoma cell line," Cancer Research, vol. 54, no. 20, pp. 5467-5473, 1994.

[34] R. Khokha, "Suppression of the tumorigenic and metastatic abilities of murine B16-F10 melanoma cells in vivo by the overexpression of the tissue inhibitor of the metalloproteinases-1," Journal of the National Cancer Institute, vol. 86, no. 4, pp. 299-304, 1994.

[35] O. A. Alvarez, D. F. Carmichael, and Y. A. DeClerck, "Inhibition of collagenolytic activity and metastasis of tumor cells by a recombinant human tissue inhibitor of metalloproteinases," Journal of the National Cancer Institute, vol. 82, no. 7, pp. 589595, 1990.

[36] R. Khokha, P. Waterhouse, S. Yagel et al., "Antisense RNAinduced reduction in murine TIMP levels confers oncogenicity of Swiss 3T3 cells," Science, vol. 243, no. 4893, pp. 947-950, 1989.

[37] T. B. Buck, H. Yoshiji, S. R. Harris, O. R. Bunce, and U. P. Thorgeirsson, "The effects of sustained elevated levels of circulating tissue inhibitor of metalloproteinases-1 on the development of breast cancer in mice," Annals of the New York Academy of Sciences, vol. 878, pp. 732-735, 1999.

[38] D. C. Martin, U. Rüther, O. H. Sanchez-Sweatman, F. W. Orr, and R. Khokha, "Inhibition of SV40 T antigen-induced hepatocellular carcinoma in TIMP-1 transgenic mice," Oncogene, vol. 13, no. 3, pp. 569-576, 1996.

[39] K. M. Finan, G. Hodge, A. M. Reynolds et al., "In vitro susceptibility to the pro-apoptotic effects of TIMP-3 gene delivery translates to greater in vivo efficacy versus gene delivery for TIMPs-1 or -2," Lung Cancer, vol. 53, no. 3, pp. 273-284, 2006.

[40] E. A. Baker, T. J. Stephenson, M. W. R. Reed, and N. J. Brown, "Expression of proteinases and inhibitors in human breast cancer progression and survival," Molecular Pathology, vol. 55, no. 5, pp. 300-304, 2002.

[41] M. D. Sternlicht and Z. Werb, "How matrix metalloproteinases regulate cell behavior," Annual Review of Cell and Developmental Biology, vol. 17, pp. 463-516, 2001.

[42] W. C. Parks, C. L. Wilson, and Y. S. López-Boado, "Matrix metalloproteinases as modulators of inflammation and innate immunity," Nature Reviews Immunology, vol. 4, no. 8, pp. 617629, 2004.

[43] S. Struyf, P. Proost, J. Vandercappellen et al., "Synergistic up-regulation of MCP-2/CCL8 activity is counteracted by chemokine cleavage, limiting its inflammatory and antitumoral effects," European Journal of Immunology, vol. 39, no. 3, pp. 843-857, 2009.

[44] A. E. Kossakowska, D. R. Edwards, C. Prusinkiewicz et al., "Interleukin-6 regulation of matrix metalloproteinase (MMP-2 and MMP-9) and tissue inhibitor of metalloproteinase (TIMP-1) expression in malignant non-Hodgkin's lymphomas," Blood, vol. 94, no. 6, pp. 2080-2089, 1999.

[45] S. Lacraz, L. Nicod, B. Galve-de Rochemonteix, C. Baumberger, J. M. Dayer, and H. G. Welgus, "Suppression of metalloproteinase biosynthesis in human alveolar macrophages by interleukin-4," Journal of Clinical Investigation, vol. 90, no. 2, pp. 382-388, 1992.

[46] S. D. Shapiro, E. J. Campbell, D. K. Kobayashi, and H. G. Welgus, "Immune modulation of metalloproteinase production in human macrophages. Selective pretranslational suppression of interstitial collagenase and stromelysin biosynthesis by interferon- $\gamma$," Journal of Clinical Investigation, vol. 86, no. 4, pp. 1204-1210, 1990.

[47] S. Lacraz, L. P. Nicod, R. Chicheportiche, H. G. Welgus, and J.-M. Dayer, "IL-10 inhibits metalloproteinase and stimulates TIMP-1 production in human mononuclear phagocytes," Journal of Clinical Investigation, vol. 96, no. 5, pp. 2304-2310, 1995.

[48] M. E. Stearns, M. Wang, Y. Hu, F. U. Garcia, and J. Rhim, "Interleukin 10 blocks matrix metalloproteinase-2 and membrane type 1-matrix metalloproteinase synthesis in primary human prostate tumor lines," Clinical Cancer Research, vol. 9, no. 3, pp. 1191-1199, 2003.

[49] I. M. Verma, J. K. Stevenson, E. M. Schwarz, D. Van Antwerp, and S. Miyamoto, "Rel/NF- $\kappa \mathrm{B} / \mathrm{I} \kappa \mathrm{B}$ family: intimate tales of association and dissociation," Genes and Development, vol. 9, no. 22, pp. 2723-2735, 1995.

[50] G. Bonizzi and M. Karin, "The two NF- $\kappa$ B activation pathways and their role in innate and adaptive immunity," Trends in Immunology, vol. 25, no. 6, pp. 280-288, 2004.

[51] C. Nakanishi and M. Toi, "Nuclear factor- $\kappa \mathrm{B}$ inhibitors as sensitizers to anticancer drugs," Nature Reviews Cancer, vol. 5, no. 4, pp. 297-309, 2005.

[52] J. Sun and W. G. Stetler-Stevenson, "Overexpression of tissue inhibitors of metalloproteinase 2 up-regulates NF-kappaB activity in melanoma cells," Journal of Molecular Signaling, vol. 4, article 4, 2009.

[53] K. Yamashita, M. Suzuki, H. Iwata et al., "Tyrosine phosphorylation is crucial for growth signaling by tissue inhibitors of metalloproteinases (TIMP-1 and TIMP-2)," FEBS Letters, vol. 396, no. 1, pp. 103-107, 1996.

[54] M. L. Corcoran and W. G. Stetler-Stevenson, "Tissue inhibitor of metalloproteinase-2 stimulates fibroblast proliferation via a cAMP-dependent mechanism," Journal of Biological Chemistry, vol. 270, no. 22, pp. 13453-13459, 1995.

[55] J. A. Nemeth, A. Rafe, M. Steiner, and C. L. Goolsby, "TIMP2 growth-stimulatory activity: a concentration-and cell typespecific response in the presence of insulin," Experimental Cell Research, vol. 224, no. 1, pp. 110-115, 1996.

[56] F. Lizárraga, V. Maldonado, and J. Meléndez-Zajgla, "Tissue inhibitor of metalloproteinases-2 growth-stimulatory activity is mediated by nuclear factor-kappa B in A549 lung epithelial cells," International Journal of Biochemistry and Cell Biology, vol. 36, no. 8, pp. 1655-1663, 2004.

[57] N. D. Perkins, "NF- $\kappa$ B: tumor promoter or suppressor?" Trends in Cell Biology, vol. 14, no. 2, pp. 64-69, 2004.

[58] J. F. Bromberg, M. H. Wrzeszczynska, G. Devgan et al., "Stat3 as an oncogene," Cell, vol. 98, no. 3, pp. 295-303, 1999. 
[59] J. E. Harris, M. Fernandez-Vilaseca, P. T. G. Elkington, D. E. Horncastle, M. B. Graeber, and J. S. Friedland, "IFN $\gamma$ synergizes with IL- $1 \beta$ to up-regulate MMP-9 secretion in a cellular model of central nervous system tuberculosis," FASEB Journal, vol. 21, no. 2, pp. 356-365, 2007.

[60] J. Dien, H. M. Amin, N. Chiu et al., "Signal transducers and activators of transcription-3 up-regulates tissue inhibitor of metalloproteinase-1 expression and decreases invasiveness of breast cancer," American Journal of Pathology, vol. 169, no. 2, pp. 633-642, 2006.

[61] M. Bugno, L. Graeve, P. Gatsios et al., "Identification of the interleukin-6/oncostatin $M$ response element in the rat tissue inhibitor of metalloproteinases-1 (TIMP-1) promoter," Nucleic Acids Research, vol. 23, no. 24, pp. 5041-5047, 1995.

[62] R. Lai, G. Z. Rassidakis, L. J. Medeiros et al., "Signal transducer and activator of transcription-3 activation contributes to high tissue inhibitor of metalloproteinase-1 expression in anaplastic lymphoma kinase-positive anaplastic large cell lymphoma," American Journal of Pathology, vol. 164, no. 6, pp. 2251-2258, 2004.

[63] J. K. Riley, K. Takeda, S. Akira, and R. D. Schreiber, "Interleukin-10 receptor signaling through the JAK-STAT pathway. Requirement for two distinct receptor-derived signals for anti-inflammatory action," Journal of Biological Chemistry, vol. 274, no. 23, pp. 16513-16521, 1999.

[64] B. E. Bachmeier, C. M. Iancu, M. Jochum, and A. G. Nerlich, "Matrix metalloproteinases in cancer: comparison of known and novel aspects of their inhibition as a therapeutic approach," Expert Review of Anticancer Therapy, vol. 5, no. 1, pp. 149-163, 2005.

[65] B. N. Gomperts and R. M. Strieter, "Chemokine-directed metastasis," Contributions to Microbiology, vol. 13, pp. 170190, 2006.

[66] V. B. Andela, A. H. Gordon, G. Zotalis et al., "NFkB: a pivotal transcription factor in prostate cancer metastasis to bone," Clinical Orthopaedics and Related Research, no. 415, supplement, pp. S75-S85, 2003. 

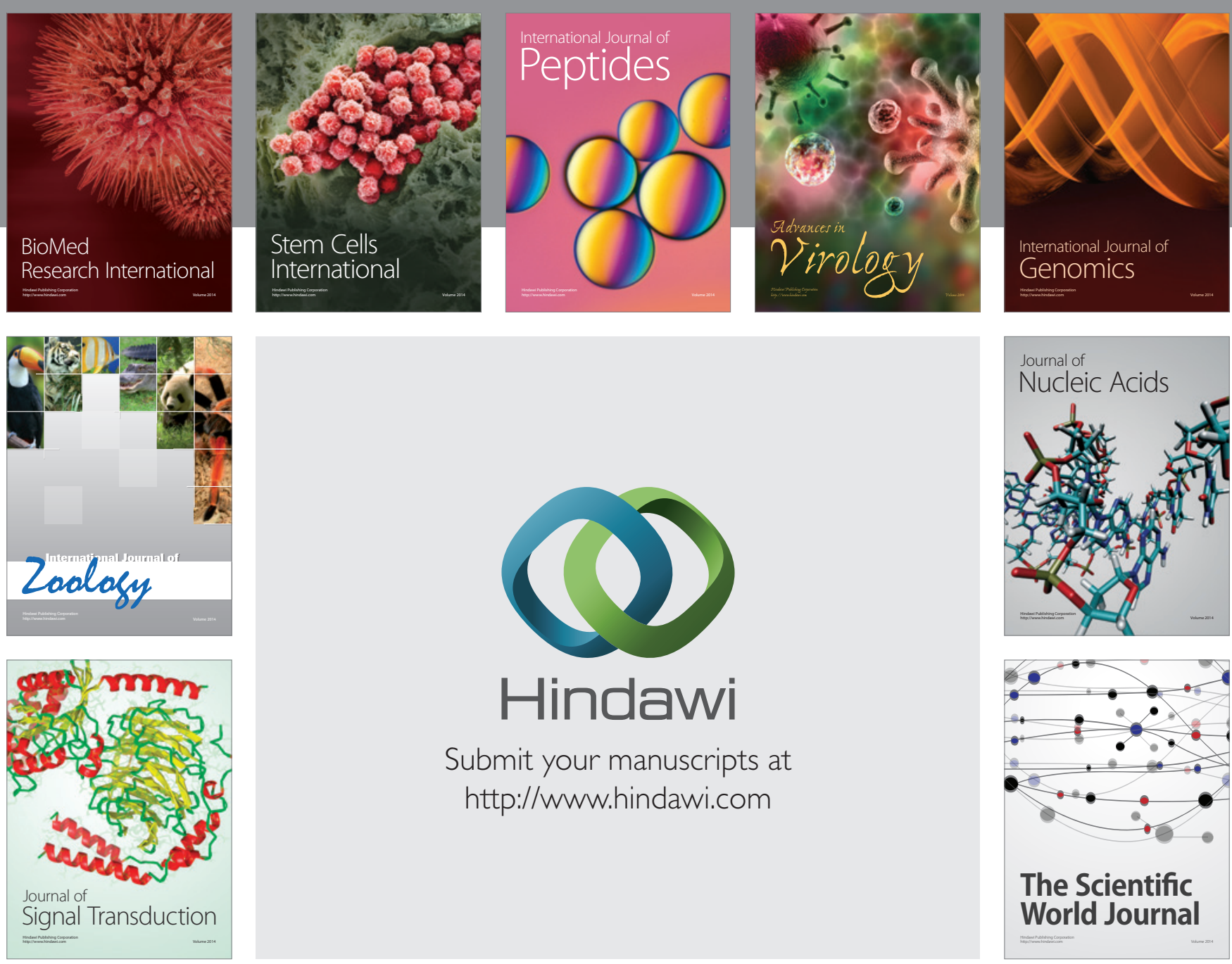

Submit your manuscripts at

http://www.hindawi.com
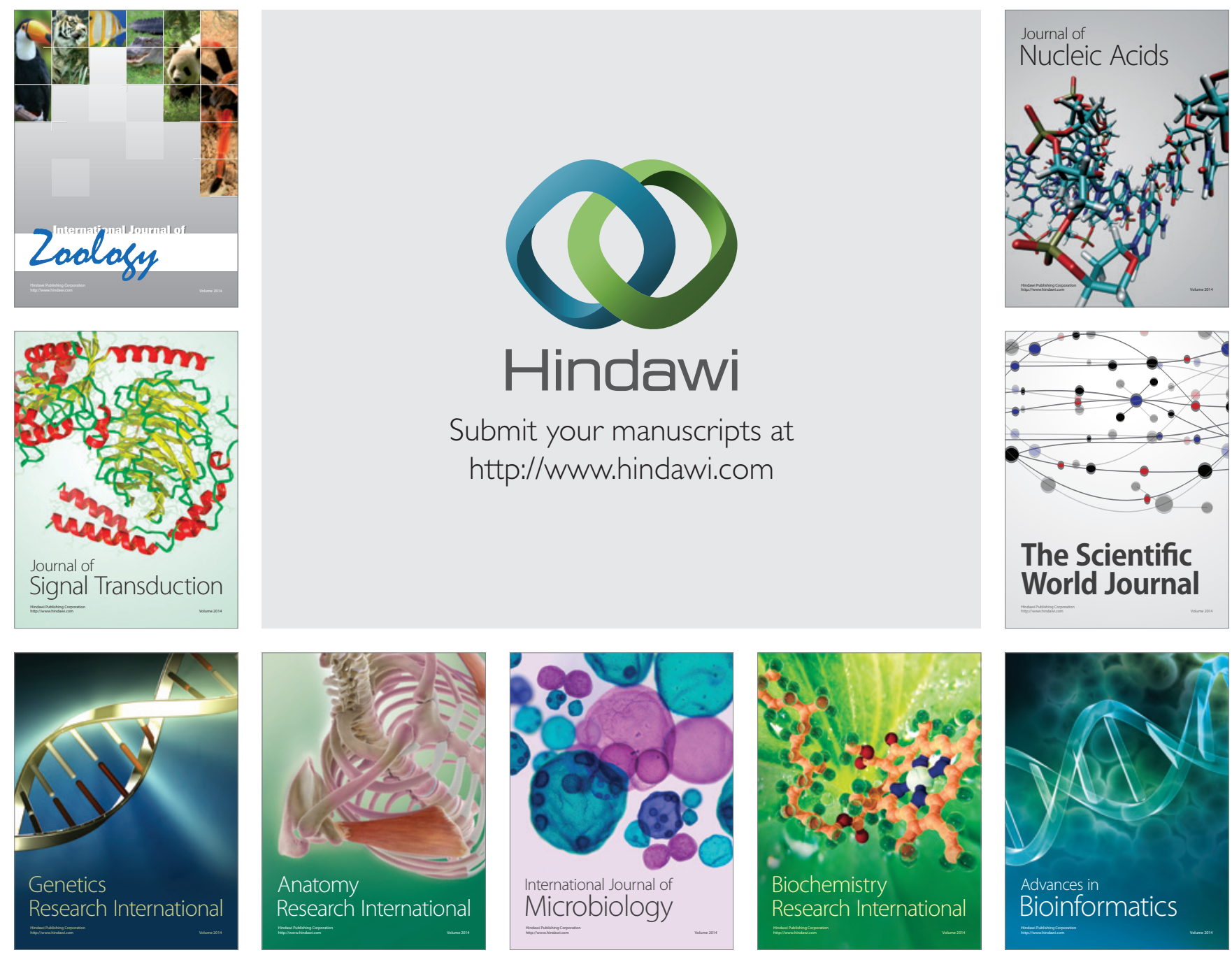

The Scientific World Journal
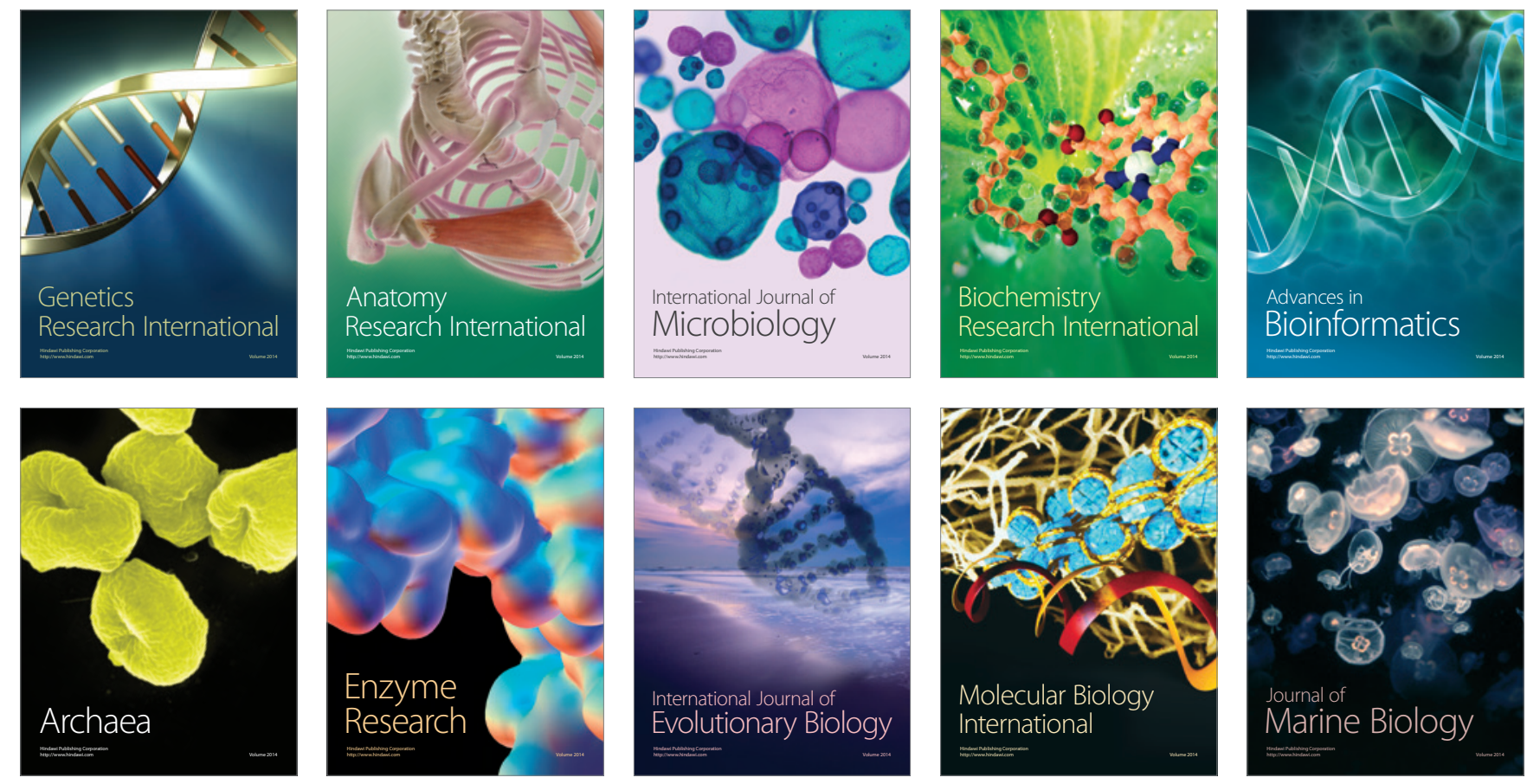